\title{
PELAKSANAAN PSN 3M PLUS TERHADAP CONTAINER INDEX DEMAM BERDARAH DI KENJERAN SURABAYA
}

Alilah Faridatul Ulfa*, Nur Haidah, Koerniasari

Jurusan Kesehatan Lingkungan, Politeknik Kesehatan Kemenkes Surabaya *Email korespondensi: alilulil93@gmail.com

\begin{abstract}
ABSTRAK
Pada tahun 2018 ada 31 daerah wabah di Kecamatan Kenjeran, salah satu daerah endemik Surabaya, dan kondisi sanitasi rumah dan tindakan masyarakat terkait dengan kejadian tersebut. Tujuan dari penelitian ini adalah mengetahui hubungan antara pelaksanaan PSN 3M plus terhadap Container Index DBD.

Jenis penelitian ini adalah deeskriptif analitik dengan sampel penderita sejumlah 29 orang. Teknik pengambilan sampel menggunakan random sampling. Pengumpulan data dan lembar observasi dan melakukan pengamatan langsung pada wadah. Analisis data dilakukan dengan analisis univariat dan tabel dalam bentuk distribusi frekuensi dan statistik inferensial yang bernilai tingkat kepercayaan $95 \%$.

Hasil penelitian menunjukkan bahwa ada hubungan antara Pemberantasan Sarang Nyamuk 3M (PSN) Plus dengan Indeks Kontainer di Kenjeran, Kota Surabaya $(p=0,000)$. Dan juga ada hubungan indeks Kontainer dengan kejadian demam berdarah (DBD) di Kenjeran Surabaya $(p=0,001)$.

Kurangnya kesadaran masyarakat tentang pentingnya mempertahankan PSN 3M Plus adalah salah satu faktor yang mempengaruhi terjadinya DBD. Sehingga masyarakat akan meningkatkan kesadaran PSN 3M, dan Pusat Kesehatan Masyarakat (Puskesmas), diharapkan dapat menambah pengetahuan tentang pentingnya Aksi PSN 3M Plus bagi masyarakat.
\end{abstract}

Kata kunci: PSN 3M Plus, Container Index, DBD

\section{PENDAHULUAN}

Indonesia merupakan negara beriklim tropis yang kaya akan keanekaragaman hayati flora dan fauna. Kondisi iklim tropis dan berbagai jenis tanah, termasuk banyaknya ragam tumbuhan Indonesia sangat mendukung bagi perkembangan makhluk hidup didalamnya. $\mathrm{Di}$ Indonesia penyakit Demam Berdarah Dengue (DBD) merupakan salah satu masalah kesehatan masyarakat yang utama, jumlah penderita DBD semakin luas seiringnya dengan meningkatnya mobilitas kepadatan penduduk terutama didaerah tropis dan sub-tropis. (Kemenkes RI, 2017)

Sejak tahun 1968 hingga tahun 2009 World Health Organization (WHO) mencatat bahwa negara Indonesia sebagai kasus DBD tertinggi di Asia Tenggara. Penyakit DBD mempunyai penyebaran yang sangat cepat dan sering terjadi banyak penderita yang meninggal akibat penanganan yang terlambat. Penyakit Demam Berdarah Dengue pertama kali ditemukan di Indonesia yaitu di Kota Surabaya sejak tahun 1968 dimana 58 orang yang terinfeksi dan 24 orang diantaranya meninggal dunia (Angka Kematian (AK): 41,3\%). (Gubbler DJ, 2009)

Dinas Kesehatan Kota Surabaya 2016 mencatat pada tahun 2015 sampai 2016 mengalami peningkatan yaitu dari 640 kasus (CFR=2\%) menjadi 938 kasus dengan jumlah kematian sebanyak 7 orang, sehingga Case Fatality Rate (CFR) sebesar 0,75\%. Pada tahun 2017 di Surabaya mengalami penurunan menjadi 325 kasus sehingga CFR sebesar 0,6\% akan tetapi hal ini tetap masih dibawah $<1 \%$ pada target nasional. (Dinas Kesehatan Kota Surabaya, 2016)

Kota Surabaya terdiri dari 31 wilayah kerja Kecamatan memiliki beberapa daerah endemis yaitu Puskesmas Tanah Kali Kedinding, Puskesmas Sidotopo Wetan, Puskesmas Bulak Banteng, dan Puskesmas Tambak Wedi, serta sebagian bebas DBD. Pada tahun 2018 terdapat wilayah endemis 
DBD yang terjadi 2 tahun terakhir yaitu wilayah Kecamatan Kenjeran sebanyak 31 penderita DBD. (Dinas Kesehatan Kota Surabaya, Laporan Tahunan , 2017)

Program penanggulangan DBD yang telah dilakukan pada Dinas Kesehatan Kota Surabaya, khususnya pada Kecamatan Kenjeran selama tahun 2018 meliputi PSN, Penyuluhan, Larvasidasi, Pemeriksaan Jentik Berkala, fogging fokus dan fogging massal. Semua program kegiatan tersebut sudah dilaksanakan di wilayah Kecamatan Kenjeran tetapi hasil yang didapatkan masih sangat jauh dari pencapaian target yang diharapkan pemerintah. Wilayah kerja Kecamatan Kenjeran jumlah penderita DBD nya dalam kategori tinggi, hal ini disebabkan salah satunya kondisi sanitasi lingkungan rumah dan perilaku tindakan masyarakat terkait dengan kejadian DBD masih dianggap bermasalah dan dapat meningkatkan resiko DBD, seperti tempat-tempat penampungan air yang positif jentik, semak-semak maupun genangan air disekitar rumah, dan keberadaan barang bekas yang dapat menampung air hujan. Faktor kepadatan penduduk juga memicu tingginya kasus DBD, karena tempat perindukan nyamuk hampir seluruhnya adalah perbuatan manusia mulai dari memelihara kaleng bekas, ban bekas hingga bak mandi. (Hastuti, Dharmawan, \& Indarto, 2017).

Sebagai pelayanan kesehatan yang mengedepankan upaya pencegahan primer dan sekunder. Dalam upaya membantu program pencegahan, promosi dan pengendalian khususnya penyakit DBD, akan sangat membantu apabila puskesmas mampu memperkirakan faktor resiko lingkungan. Tujuan penelitian ini untuk mengetahui adanya hubungan tindakan PSN 3M Plus terhadap Container Index DBD di Kenjeran Surabaya.

\section{METODE PENELITIAN}

Penelitian dilakukan di wilayah kerja Puskesmas Kecamatan Kenjeran,
Kota Surabaya. Pemilihan lokasi ini didasarkan karena Kecamatan Kenjeran merupakan salah satu daerah endemis di Kota Surabaya berdasarkan data dari Dinas Kesehatan Kota Surabaya tahun 2018. Penelitian ini dilaksanakan pada bulan Oktober 2018 - April 2019.

Jenis penelitian yang digunakan adalah penelitia observasional analitik, yaitu peneliti melakukan observasi (pengamatan) dan menganalisis hubunga variabel bebas dengan variabel terikat berdasarkan terois. Penelitian ini menggunakan desain case contro/ adalah suatu penelitian analitik yang digunakan untuk menyelidiki orang-orang yang menderita penyakit atau efek (kasus) yang hendak diselidiki penyebabnya (faktor risiko), dibandingkan dengan orang-orang yang tidak menderita penyakit atau efek tersebut (kontrol). Sampel dalam penelitian ini adalah 29 penderita DBD dan 29 kontrol dimana kontrol adalah tetangga terdekat dari rumah penderita $\mathrm{DBD}$.

Data primer didapatkan dari hasil observasi dengan menggunakan lembar observasi untuk mengetahui tindakan terhadap Pemberantasan Sarang Nyamuk Plus dan Container Index. Data sekunder didapatkan dari dari Dinas Kesehatan Kota mengenai jumlah penderita DBD terbesar di Kecamatan yang terdapat di Kota Surabaya dan data dari Puskesmas Sidotopo Wetan, Bulak Banteng, Tambak Wedi, dan Tanah Kali Kedinding mengenai jumlah penderita DBD beserta alamat penderita DBD.

Pengolahan data dilakukan dengan menggunakan SPSS (Statistical Package and Social Siences). Model analisis univariat dan bivariat. Data yang telah dianalisis disajikan dalam bentuk tabel, dan narasi untuk mengetahui hubungan tindakan pemberantasan sarang nyamuk (PSN) 3M plus di Kecamatan Kenjeran Kota Surabaya. 
HASIL DAN PEMBAHASAN

Tabel 1

HUBUNGAN TINDAKAN PSN 3M PLUS DENGAN CONTAINER INDEX DI KENJERAN SURABAYA

\begin{tabular}{|c|c|c|c|c|c|}
\hline \multirow{3}{*}{$\begin{array}{c}\text { Tindakan PSN 3M } \\
\text { Plus }\end{array}$} & \multicolumn{4}{|c|}{ Container Index } & \multirow{3}{*}{$p$-value } \\
\hline & \multicolumn{2}{|c|}{$\begin{array}{c}\text { Risiko Penularan } \\
\text { Tinggi }\end{array}$} & \multicolumn{2}{|c|}{$\begin{array}{l}\text { Risiko Penularan } \\
\text { Rendah }\end{array}$} & \\
\hline & $\mathrm{n}$ & $\%$ & $\mathrm{n}$ & $\%$ & \\
\hline Kurang Baik & 25 & 86,2 & 4 & 13,8 & \\
\hline $\begin{array}{l}\text { Baik } \\
\text { Total }\end{array}$ & $\begin{array}{c}6 \\
31\end{array}$ & $\begin{array}{c}20,7 \\
100\end{array}$ & $\begin{array}{l}23 \\
27\end{array}$ & $\begin{array}{l}79,3 \\
100\end{array}$ & 0,000 \\
\hline
\end{tabular}

Berdasarkan tabel 1 dapat diketahui bahwa dari hasil penelitian tindakan responden dalam melakukan pemberantasan sarang nyamuk (PSN) 3M PLUS dengan tindakan yang kurang baik dan mempunyai risiko penularan tinggi sebanyak 25 orang $(86,2 \%)$, sedangkan tindakan yang kurang baik yang mempunyai risiko penularan rendah sebanyak 4 orang $(13,8 \%)$. Tindakan PSN 3M PLUS dalam kategori baik dan yang mempunyai risiko penularan tinggi sebanyak 6 orang $(20,7 \%)$, sedangkan pada yang mempunyai risiko penularan rendah sebanyak 23 orang (79,3\%).

Hasil analisis bivariat antara tindakan dengan container index di wilayah Kecamatan Kenjeran Kota Surabaya dengan menggunakan uji Chi-square menunjukkan bahwa tindakan memiliki nilai $\rho$ value sebesar 0,000 atau $\rho$ value < $a(0,05)$, maka $\mathrm{H} 0$ ditolak yang artinya ada hubungan antara tindakan PSN 3M PLUS dengan container index di wilayah Kecamatan Kenjeran Kota Surabaya.

Hasil penelitian mengenai tindakan PSN 3M Plus dengan Container index responden menunjukkan bahwa $\rho$ value $=$ 0,000 . Sehingga dapat disimpulkan bahwa H0 ditolak dan H1 diterima, sehingga tindakan PSN 3M PLUS responden mempunyai hubungan terhadap container index di Kecamatan Kenjeran Kota Surabaya Tahun 2019.

Dalam hal tindakan PSN 3M PLUS, dapat diketahui bahwa yang memiliki tindakan yang kurang baik dan mempunyai risiko penularan tinggi sebanyak 25 orang $(86,2 \%)$, sedangkan tindakan yang kurang baik yang mempunyai risiko penularan rendah sebanyak 4 orang $(13,8 \%)$. Tindakan PSN 3M PLUS dalam kategori baik dan yang mempunyai risiko penularan tinggi sebanyak 6 orang $(20,7 \%)$, sedangkan pada yang mempunyai risiko penularan rendah sebanyak 23 orang $(79,3 \%)$.

Penelitian ini sesuai dengan penelitian Nani dan Hargono (2016) bahwa ada hubungan antara tindakan responden terhadap keberadaan jentik dengan nilai $\rho v a / u e 0,000$. Penelitian ini juga didukung oleh Putri, Adrial dan Irawati (2016) bahwa ada hubungan antara perilaku subjek penelitian dengan keberadaan jentik.

Berdasarkan hasil observasi ditemukan bahwa responden masih menunjukkan tindakan terhadap pemberantasan sarang nyamuk (PSN) 3M PLUS kurang peduli untuk menguras bak mandi seminggu sekali dan tidak menutup tempat penampungan air. Hal ini mengakibatkan masih banyaknya ditemukan keberadaan jentik di tempat penampungan air di sekitar rumah. Responden jarang melakukan kegiatan tersebut sehingga menurut Kemenkes RI (2012) kegiatan PSN dinilai sangat efektif untuk mencegah berkembangnya nyamuk serta memberantas sarang nyamuk. Selain itu masih banyaknya ditemukannya masyarakat yang menggantung pakaian di dinding ataupun di belakang pintu serta menyimpan barang bekas seperti kaleng bekas, botol bekas, dan gelas bekas. Hal ini dapat mengundang nyamuk dan dijadikan tempat peristirahatan nyamuk. Sehingga dapat mengakibatkan tingginya tingkat risiko penularan penyakit Demam Berdarah Dengue. 
Berdasarkan teori Notoatmodjo, S (2012), bahwa terbentuknya perilaku baru pada individu seseorang dimulai dari seseorang tahu terlebih dahulu terhadap stimulus yang berupa materi atau objek sehingga menimbulkan pengetahuan baru pada seseorang tersebut. Perilaku ini dapat dikaitkan dengan usaha seseorang untuk memelihara dan meningkatkan kesehatannya. Pemberantasan sarang nyamuk dengan metode $3 \mathrm{M}$ Plus merupakan salah satu kegiatan yang dilakukan setiap orang secara mandiri sebagai langkah untuk pencegahan terhadap penyakit menular vektor Aedes aegypti khususnya untuk penyakit DBD. Dalam penelitian tersebut dapat disimpulkan bahwa ada pengaruh tindakan tentang pemberantasan sarang nyamuk (PSN) 3M PLUS yang buruk adalah faktor resiko kejadian penyakit Demam Berdarah Dengue (DBD).

Tabel 2

HUBUNGAN CONTAINER INDEX DENGAN KEJADIAN DBD DI KECAMATAN KENJERAN

\begin{tabular}{|c|c|c|c|c|c|}
\hline \multirow{3}{*}{ Container Index } & \multicolumn{4}{|c|}{ Kejadian DBD } & \multirow[b]{3}{*}{$p$-value } \\
\hline & \multicolumn{2}{|c|}{ Kasus } & \multicolumn{2}{|c|}{ Kontrol } & \\
\hline & $\mathrm{n}$ & $\%$ & $\mathrm{~N}$ & $\%$ & \\
\hline Resiko Penularan Tinggi & 20 & 69 & 7 & 24,1 & \\
\hline Resiko Penularan Rendah & 9 & 31 & 22 & 75,9 & 0,001 \\
\hline Total & 29 & 100 & 29 & 100 & \\
\hline
\end{tabular}

Berdasarkan tabel 2 dapat diketahui bahwa dari hasil penelitian container index jumlah responden pada kelompok kasus, penyakit DBD banyak responden yang resiko penularan tinggi dengan hasil Container Index $>10 \%$ yaitu sebanyak 20 orang (69\%). Sedangkan responden pada kelompok kontrol, responden banyak yang berisiko penularan rendah dengan hasil Container Index $<10 \%$ sebanyak 22 orang $(75,9 \%)$.

Hasil analisis bivariat antara Container Index dengan kejadian DBD pada responden di wilayah Kecamatan Kenjeran menunjukkan bahwa hasil perhitungan Container Index memiliki nilai pvalue sebesar 0,001 atau pvalue < $a$ $(0,05)$, maka HO ditolak yang artinya ada hubungan antara Container Index dengan kejadian DBD di wilayah Kecamatan Kenjeran Kota Surabaya.

Penularan penyakit Demam Berdarah Dengue (DBD) dapat dicegah dengan melakukan pemberantasan sarang nyamuk dewasa dan pemberantasan larva atau jentik Aedes aegypti. Pemberantasan Sarang Nyamuk (PSN) dapat dilakukan dengan cara melaksanakan 3M Plus yang terdiri dari menguras tempat penampungan air (TPA) seminggu sekali, menutup TPS, mengubur barang bekas terutama saat musim penghujan tiba, plus menggati air vas bunga dan tempat minum burung seminggu sekali, memperbaiki talang air yang rusak, menutup lubang pohon dengan tanah. Oleh karena itu, masyarakat diharapkan untuk mampu meningkatkan tindakan pencegahan penularan penyakit DBD dengan melakukan Pemberantasan Sarang Nyamuk (PSN) melalui 3M Plus secara teratur (Kemenkes, 2012).

Berdasarkan hasil penelitian menunjukkan bahwa terdapat hubungan antara kepadatan jentik yang dinilai dari Container Index (CI) dengan kejadian DBD di Kecamatan Kenjeran Kota Surabaya. Penelitian ini sesuai dengan penelitian yang dilakukan oleh Nunik Maya Hastuti (2017) yang menyatakan bahwa Container Index (CI) mempunyai hubungan yang bermakna secara statistik terhadap kasus DBD $\quad(p=0,001)$. Penelitian yang dilakukan oleh Zulmi Indriyani pada tahun 2015 juga menyatakan bahwa responden dengan rumah yang memiliki angka Container Index (CI) berisiko tinggi lebih besar untuk terkena DBD dibandingkan responden dengan rumah yang memiliki angka Container Index (CI) berisiko rendah. Keberadaan jentik di tempattempat penampungan air responden sangat erat hubungannya dengan tindakan pencegahan yang dilakukan. Hal ini menunjukkan bahwa masih terdapat masyarakat di Kecamatan Kenjeran yang 
belum melakukan tindakan berupa pencegahan penyakit DBD yang paling efektif, yaitu pelaksanaan 3M Plus secara teratur.

Nilai Container Index pada kelompok kasus yang mempunyai resiko penularan rendah sebanyak $31 \%$ dan yang resiko penularan tinggi sebanyak $69 \%$. Sedangkan pada kelompok kontrol yang mempunyai resiko penularan rendah sebanyak $75,9 \%$ dan yang resiko penularan tinggi sebanyak $24,1 \%$. Menurut WHO, dikatakan berisiko tinggi untuk penularan DBD jika Container Index $\geq 10 \%$. Tingginya kepadatan populasi jentik akan mempengaruhi distribusi penyebaran penyakit DBD. Hal ini karena ada asumsi bahwa kurang dari $10 \%$ dari suatu populasi nyamuk yang ada pada musim penularan akan menjadi vektor. Selain itu, kepadatan nyamuk akan berpengaruh terhadap ketahanan hidupnya terutama hubungannya dengan ancaman musuh/predator.

Begitu pula dengan penelitian Amrieds (2016) yang menunjukkan bahwa ada hubungan antara keberadaan jentik pada kontainer dengan kejadian DBD. Hal ini dikarenakan responden belum secara maksimal memutus rantai perkembangbiakan nyamuk dengan cara membasmi jentik-jentik nyamuk dengan melakukan 3M Plus sehingga tidak sampai menjadi nyamuk dewasa. Salah satunya dikarenakan kurangnya pengetahuan masyarakat dalam pemakaian larvasida (abate) yang benar. Kegiatan 3M Plus harus sering dilakukan oleh masyarakat di lingkungan tempat tinggalnya masingmasing. Sehingga diharapkan puskesmas setempat memberikan petunjuk pemakaian larvasida (abate) yang benar kepada masyarakat melalui bantuan kader setempat.

\section{KESIMPULAN}

Berdasarkan penelitian dapat disimpulkan bahwa ada hubungan antara tindakan pemberantasan sarang nyamuk (PSN) 3M PLUS terhadap container index juga terhadap kejadian DBD di Kecamatan Kenjeran Kota Surabaya.

\section{SARAN}

Bagi Masyarakat pelaksanaan kegiatan PSN 3M PLUS secara rutin, terkait menguras tempat penampungan air terutama bak mandi, menutup tempat penampungan air, dan memantau jentik di Tempat Penampungan Air (TPA) agar perkembangbiakan nyamuk dapat terhambat. Bagi Dinas Kesehatan Kota Surabaya, pelaksanaan promosi kesehatan dalam hal tindakan PSN 3M Plus, kerja bakti atau pun program yang sejenis dilingkungan rumah ataupun lingkungan kelurahan, bagi para warganya secara berkala.

\section{DAFTAR PUSTAKA}

Amrieds, E. T., Asfian, P., \& Ainurafiq. (2016). Faktor - faktor yang Berhubungan dengan Kejadian Demam Berdarah Dengue (DBD) di Kelurahan 10 November Kecamatan Wundulako Kabupaten Kolaka .

Dinas Kesehatan Kota Surabaya. (2016). Profil Dinas Kesehatan Kota Surabaya Tahun 2016. Surabaya: Dinas Kesehatan Surabaya.

Dinas Kesehatan Kota Surabaya. (2017). Laporan Tahunan. Surabaya: Dinas Kesehatan Surabaya.

Gubbler DJ. (2009). Epidemic Dengue/Dengue Hemorrhagic Fever as Public Health. Social and Economic

Hastuti, N., Dharmawan, R., \& Indarto, D. (2017). Sanitation-Related Behavior, Container Index, and Their Associations with Dengue Hemorrhagic Fever Incidence. Journal of Epidemiology and Public Health.Problem in 21st Century: Trends in Microbiology.

Indriyani, z., Rahardjo, M., \& Setiani, O. (2015). Hubungan Faktor Lingkungan dengan Persebaran Kejadian Demam Berdarah Dengue (DBD) di Kecamatan Jepara Kabupaten Jepara. Jurnal Kesehatan Masyarakat, 847-848.

Kementrian Kesehatan Republik Indonesia. (2017). Profil Kesehatan Indonesia 2016. Jakarta.

Kementrian Kesehatan Republik Indonesia. (2012). Juknis Pemberantasan Sarang Nyamuk 
Dengue (PSN DBD). Jakarta: Menkes RI Dirjen P2PL .

Nani, \& Hargono, A. (2016). Hubungan Perilaku PSN dengan Keberadaan Jentik Aedes aegypti di Pelabuhan Pulang Pisau. Jurnal Epidemiologi. Notoatmodjo, S. (2012). Promosi Kesehatan dan Perilaku Kesehatan. Jakarta: Rineka Cipta.
Putri, M. D., Adrial, \& Irawati, L. (2016). Hubungan Tindakan Pemberantasan Sarang Nyamuk (PSN) dengan Keberadaan Jentik Vektor Chikungunya di Kampung Taratak Paneh Kota Padang. Jurnal Kesehatan Andalas, 500-502. 